\title{
View of simple clusters by scattering
}

\section{Citlali Sánchez Aké, Mayo Villagrán-Muniz, Ana Martínez}

Citlali Sánchez Aké, Mayo Villagrán-Muniz, Ana Martínez, "View of simple clusters by scattering," Proc. SPIE 9663, Eighth International Topical Meeting on Education and Training in Optics and Photonics, 96631V (6 October 2003); doi: $10.1117 / 12.2208477$

SPIE Event: Eighth International Topical Meeting on Education and Training in Optics and Photonics, 2003, Tucson, Arizona, United States 


\title{
View of simple clusters by scattering
}

\author{
Citlali Sánchez Aké and Mayo Villagrán-Muniz \\ Laboratorio de Fotofisica, Centro de Ciencias Aplicadas y Desarrollo Tecnológico, UNAM, A.P. 70-186, C. P. 04510, México, D. F. \\ telephone: (52 55) 56228614 - ext.115; fax: (52 55) 56228651; e-mail: mayo@aleph.cinstrum.unam.mx
}

\author{
Ana Martínez \\ Instituto de Investigaciones en Materiales, UNAM, Circuito Exterior S.N. Ciudad Universitaria. Apdo. \\ Postal 70-360, C. P. 04510, México, D. F.
}

\begin{abstract}
We present a simple experiment to visualize water cluster formation by light scattering during an adiabatic expansion. Undergraduate students can easily perform the experiment and learn about cluster formation, cloud creation, and adiabatic expansions. (C)2003 Optical Society of America

OCIS codes: (290.5850) Scattering, particles; (000.2060) Education
\end{abstract}

\section{Summary}

Each of us has images of Nature that are stored in our memories. However, the things that we can see are not all the things that exist in the world around us. In these experiments, scattering shows clusters that are impossible to see at naked eye.

To perform the experiment, we pass a light beam through a small glass recipient in which vacuum has been made by sucking air out using the mouth. When the pressure decreases, an adiabatic expansion takes place, water clusters begin to grow and they are easily seen due to the light scattering they produce.

Clusters can be formed by adiabatic expansion in complex systems and here we explore the simplest way to produce them. If we fill the reactor with dry air or nitrogen, the scattering phenomena is not present and we demonstrate that the clusters are due to the humidity of air. The evolution of the scattered light intensity at different angles allows us to measure the droplet size ${ }^{[1]}$. The light probe beam can be a flash lamp or a laser pointer, the second one allowing more resolution.

This experiment was used with two groups of students (age 12-14 and undergraduates). After one student inhales the air inside the flask, the first question posed is: what happened in the glass flask when you remove the air? With this question, teachers explore previous ideas that the students have about the phenomena. After that, the experiment is repeated with the probe beam. In general, for younger students the idea of vacuum is very difficult to understand while older students do not have the idea of cluster formation.

Scattering helps to show and teach several topics in nano-sciences, such as cloud formation an adiabatic expansion.

[1] P.E. Wagner, Journal of Colloid and Interface Science, Vol. 53, No. 3, pp. 439-46, 1975.

Eighth International Topical Meeting on Education and Training in Optics and Photonics,

edited by Barry L. Shoop, Grover Swartzlander Jr., Proc. of SPIE Vol. 9663, 96631V

(C) 2003 SPIE, OSA, ICO · doi: 10.1117/12.2208477

Proc. of SPIE Vol. $966396631 \mathrm{~V}-1$ 